\title{
Conformational Studies of Zn-Ligand-Hexose Diastereomers Using Ion Mobility Measurements and Density Functional Theory Calculations
}

\author{
Michael D. Leavell, Sara P. Gaucher, ${ }^{*}$ and Julie A. Leary \\ University of California, Berkeley, Berkeley, California, USA
}

John A. Taraszka and David E. Clemmer

Indiana University, Bloomington, Indiana, USA

\begin{abstract}
Ion mobility studies and density functional theory calculations were used to study the structures of $[\mathrm{Zn} / \text { diethylenetriamine/Hexose } / \mathrm{Cl}]^{+}$complexes in an effort to probe differences in the three-dimensional conformations. This information allows us to gain insight into the structure of these complexes before collisional activation, which is the first step in understanding the stereoselective dissociations observed under collisionally activated conditions. The collision cross sections obtained from the ion mobility measurements showed that the mannose structure is more compact than the galactose and glucose complexes, respectively. Using density functional theory, candidate structures for each of the experimentally observed complexes were generated. Two criteria were used to determine the most likely structures of these complexes before activation: (1) The allowed relative energies of the molecules (between $0-90 \mathrm{~kJ} / \mathrm{mol}$ ) and (2) collision cross section agreement (within $2 \%$ ) between the theoretically determined structures and the experimentally determined cross section. It was found that the identity of the monosaccharide made a difference in the overall conformation of the metal-ligand-monosaccharide complex. For glucose and galactose, metal coordination to $\mathrm{O}(6)$ was found to be favorable, with the monosaccharide occupying the ${ }^{4} \mathrm{C}_{1}$ chair conformation, while for mannose, $\mathrm{O}(2)$ metal coordination was found with the monosaccharide in a $\mathrm{B}_{3,0}$ conformation. Coordination numbers varied between four and six for the $\mathrm{Zn}$ (II) metal centers. Given these results, it appears that the stereochemistry of the monosaccharide influences the conformation and metal coordination sites of the $\mathrm{Zn}(\mathrm{II}) /$ monosaccharide/dien complex. These differences may influence the dissociation products observed under collisionally activated conditions. (J Am Soc Mass Spectrom 2002, 13, 284-293) (C 2002 American Society for Mass Spectrometry
\end{abstract}

$\mathrm{T}$ The use of ion mobility mass spectrometry (IMMS), in combination with theoretical methods to gain insight into the gas phase 3-dimensional structure of biomolecules, is now a well established technique [1-7]. Numerous examples of these types of studies can be found in the literature. For example, the conformation of peptide ions has been examined to determine how the gas phase structure mimics the solution phase structure [3], or how the substitution of different metal ions for protons affects the overall conformation of peptide chains [4]. Simple amino acids have been investigated by IMMS to determine if they

Published online January 22, 2002

Address reprint requests to Dr. J. A. Leary, Department of Chemistry, University of California, Berkeley, Berkeley, CA 94720. E-mail: leary@socrates.berkeley.edu

* Current address: Buck Institute for Age Research, Novato, CA 94947. are zwitterions in the gas phase as in solution [5]. IMMS has also been used as a technique to separate opiates and opiate metabolites [6] or even peptide mixtures [7].

In this study, the gas phase structures of the three biologically relevant monosaccharides complexed with $\mathrm{Zn}$ (II)/diethylenetriamine are explored in an effort to probe the conformational differences among the complexes. The information gained aids the understanding of the coordination sites of metal ions to monosaccharides, and helps to explain what conformations are observed when diastereomers are coordinated to a metal center. This knowledge may help to explain metal-carbohydrate interactions in more complex systems. Several examples of metal-carbohydrate interactions can be found in the literature [8-13] and the importance of this subject is underscored by a recent review article [8]. Metal-carbohydrate interactions are known to occur in many biological processes. One such 
example is found in the process of cell adhesion, where the interaction of C-type lectins with oligosaccharides on cell surfaces is dependent on the Ca(II) metal ion [9]. In addition, metalloenzymes that metabolize carbohydrates, frequently utilize metals to align carbohydrate moieties properly in the active site [8, 10]. Metalcarbohydrate complexes have also been exploited in the design of therapeutic agents such as those used in the treatment of iron overload [11] or iron deficiency [12, 13].

In our laboratory, metal-carbohydrate interactions are utilized for analytical purposes [14-21]. The diastereomeric monosaccharide/metal-ligand complexes dissociate uniquely when the complexes are subjected to collision induced dissociation, yielding product ions that are indicative of the stereochemistry of the monosaccharide. This technique has been shown to be applicable to the hexoses $[14-17,20]$, hexosamines [18, 21], and the $N$-acetyl hexosamines [19]. From the ion mobility studies, we can determine the initial structures of the metal/ligand/sugar complexes before collisional activation. This information can be further used to elucidate the stereoselective dissociation mechanisms. Furthermore, these studies will aid in the understanding of metal-carbohydrate interactions, which are important in many biological processes.

\section{Experimental}

\section{Solutions for MS}

Samples were prepared as described previously [15]. Briefly, $0.5 \mathrm{mg}$ of the monosaccharide and $0.5 \mathrm{mg}$ of $\mathrm{Zn}$ (diethylenetriamine) ${ }_{2} \mathrm{Cl}_{2}$ were dissolved in $50 \mu \mathrm{L}$ of methanol. The reaction mixture was heated at $70{ }^{\circ} \mathrm{C}$ for 20 min.; after which time $1 \mu \mathrm{L}$ was diluted in $500 \mu \mathrm{L}$ of $100 \%$ methanol and analyzed.

\section{Quadrupole Ion Trap Mass Spectrometry}

Stereochemical differentiation experiments were performed as reported previously [15].

\section{Ion Mobility Mass Spectrometry}

General. Ions representing $\mathrm{Zn} /$ diethylenetriamine/ hexose/diastereomers were formed by electrospraying $1 \mathrm{mM}$ of the complex in methanol. The ESI/highpressure high-resolution IM/TOFMS instrument used in these studies has been discussed previously by Clemmer et al. [22, 23]; a brief summary is given here. Drift times $\left(t_{d}\right)$ in the IM instrument and flight times $\left(t_{f}\right)$ in the MS instrument are measured using a nested acquisition scheme, described previously [22]. Nested drift(flight) time measurements are initiated by injecting a $300 \mu$ s pulse of ions into the $58 \mathrm{~cm}$ drift tube. The drift tube is operated at a pressure of $\sim 160$ torr and an electric field strength of $137.4 \mathrm{~V} \mathrm{~cm}^{-1}$. These conditions ensure that ions drift under low field conditions [24], i.e., drift velocities are small when compared to the thermal velocity of the helium buffer gas. The position and shape of a drift time peak depends upon the average cross section of the different conformations that are sampled as the ions drift through the buffer gas as well as the dynamics of the ion-helium collisions. For ions of a given charge state, compact conformations generally have lower drift times than more open conformations.

A key feature in these experiments is the timing of the IM and TOF measurements. Flight times occur on the microsecond timescale while drift times occur on the millisecond timescale. With this arrangement, many flight time distributions can be recorded within individual drift time windows. This allows information about mobilities and $m / z$ to be recorded for all ions present in the mixture in a single experimental sequence [22]. We refer to the two-dimensional IM-TOF datasets that are recorded with this approach as nested drift(flight) time data, denoted as $t_{d}\left(t_{f}\right)$ and reported in units of $m s(\mu s)$.

\section{Determination of Experimental Cross Section}

It is often useful to derive cross sections from the experimental drift time data. Collision cross sections are inversely proportional to the mobility of an ion through the buffer gas, and are obtained from the relation [2]

$$
\Omega=\frac{(18 \pi)^{1 / 2}}{16} \frac{z e}{\left(k_{b} T\right)^{1 / 2}}\left(\frac{1}{m_{I}}+\frac{1}{m_{H e}}\right)^{1 / 2} \frac{760 E T}{273.2 L P N} t_{d}
$$

where $E$ is the electric field strength in the drift tube, $L$ is the length of the drift tube, $P$ is the buffer gas pressure, $z$ is the charge state, $N$ is the neutral number density, $T$ is the drift tube temperature, $k_{b}$ is Boltzmann's constant, $e$ is the electronic charge, and $m_{I}$ and $m_{\mathrm{He}}$ are the masses of the complex and helium, respectively. Cross sections of the theoretically determined geometries were calculated using a trajectory based method [25]. In this method, atoms (in the theoretical structure) interact with the buffer gas atom along realistic potential surfaces and the dynamics of buffer gas scattering are taken into account.

\section{Theoretical Calculations}

Individual monosaccharide structures were generated using Spartan 4.1.1 [26]. Structures were first minimized using the Sybyl force field [27] to obtain low energy starting structures and then submitted to geometry optimizations using the ONIOM method [28, 29] as employed in Gaussian 98 for Windows [30]. Using the ONIOM method, the molecules were treated by dividing the molecules into high and low level theory regimes. The high regime included the transition metal and all coordinating atoms or atoms that could be accessed by the metal (for coordination) during the 


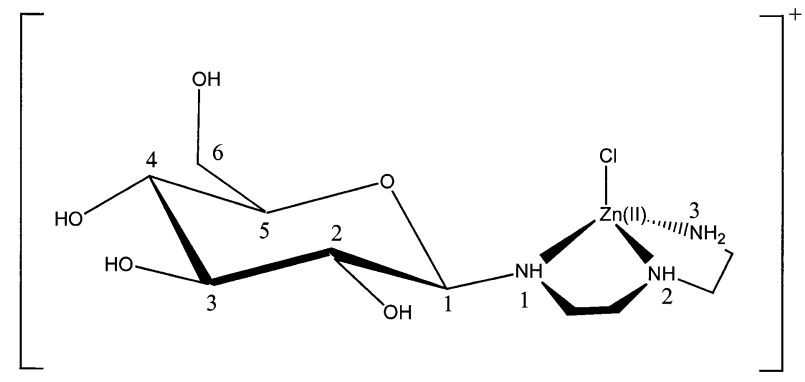

Figure 1. The $[\mathrm{Zn} / \text { dienethylenetriamine } / \text { hexose } / \mathrm{Cl}]^{+}$complex, the carbons and nitrogens are numbered according to the nomenclature used in the text.

optimization. All other atoms were treated at a lower level of theory. The high level of theory employed was SVWN/6-31G*, while the low level of theory was the semi-empirical method AM1 [31]. Upon completion of the geometry optimization, accurate energies of the completed structures were calculated at the B3LYP/6$31+\mathrm{G}^{*}$ level of theory.

\section{Results and Discussion}

A previous study has shown that stereochemical differentiation of the hexose monosaccharides can be accomplished through metal-ligand derivatization followed by collision induced dissociation (CID) in a quadrupole ion trap [15]. This method applies to the three biologically relevant monosaccharides: glucose (Glc), galactose (Gal), and mannose (Man) when the $\mathrm{Zn}(\mathrm{II}) /$ diethylenetriamine metal-ligand system is employed. The $\mathrm{Zn}(\mathrm{II}) /$ diethylenetriamine/Hexose ( $\mathrm{Zn}(\mathrm{II}) /$ dien/Hex) complex is formed through a condensation reaction between the $\mathrm{C}-1$ carbon of the sugar and a primary amine of the diethylenetriamine (dien) ligand. The resulting complex is shown in Figure 1 for the glucose analog. Synthesis of N-glycosides using metal-ligand complexing agents is well documented in the literature [14-21, 32, 33].

Stereochemical differentiation is achieved through subjecting either the deprotonated complex [Zn(II)/ dien/Hex $-\mathrm{H}^{+}(m / z$ 328) or the chlorinated complex $[\mathrm{Zn}(\mathrm{II}) / \operatorname{dien} / \mathrm{Hex} / \mathrm{Cl}]^{+}(\mathrm{m} / \mathrm{z} 364)$ to collisionally activated conditions. Differentiation of Glc, Gal, and Man can be accomplished from $\mathrm{MS}^{2}$ of the deprotonated precursor, based on the absence or presence of the product ions: $\left[\mathrm{M}-\mathrm{H}_{2} \mathrm{O}\right]^{+},\left[\mathrm{M}-\mathrm{C}_{3} \mathrm{H}_{6} \mathrm{O}_{3}\right]^{+}$, and $[\mathrm{M}-$ $\left.\mathrm{C}_{4} \mathrm{H}_{6} \mathrm{O}_{3}\right]^{+}$(Table 1) [15]. To differentiate between the three diastereomers using the chloride adduct, an $\mathrm{MS}^{3}$ experiment must be conducted. In the $\mathrm{MS}^{3}$ experiment $(364 \rightarrow 328 \rightarrow)$, the first generation product ion representing loss of $\mathrm{HCl}(\mathrm{m} / \mathrm{z} 328)$ is activated to yield stereospecific second generation product ions (Table 1).

Given these results, it is interesting to investigate the initial structures of these complexes before collisional activation. These ground state structures can then be used as a starting place for the stereoselective dissociation mechanisms, which will be probed in a further study. Using ion mobility and DFT calculations the likely structures of these complexes can be determined through comparison of the theoretical and experimental cross sections, as well as the relative energies of each of the theoretically determined complexes.

Ion mobilities (or collision cross sections) are measured by introducing pulses of ions into a well-defined drift region and recording the time required for ions to drift across this region under the influence of a uniform electric field [22, 23, 34, 35]. Figure 2 shows the ion mobility data for the $\mathrm{Zn} /$ dien/Hex/ $\mathrm{Cl}$ diastereomers, which have been plotted on a drift time scale as described previously [2]. The distribution of each of these three complexes are dominated by single peaks which indicate that one major conformation for each complex is present. However, several minor peaks are observed in the Gal and the Glc distributions, and are indicative of minor conformations that also exist over the timescale of the experiment (ms). The $\mathrm{Zn} /$ dien/ Man/Cl system $\left(\Omega=96.3+/-0.2 \AA^{2}\right)$ favors a structure that is more compact than the Gal $(\Omega=100.0+/-$ $\left.0.4 \AA^{2}\right)$ and the Glc $\left(\Omega=101.2+/-0.7 \AA^{2}\right)$ systems.

Initial geometries (for the DFT calculations) were generated in Spartan 4.1.1 [26] by starting the monosaccharide in various ring conformations (i.e., chair, boat etc.) and as the beta anomer. Previous studies have shown that synthesis of $\mathrm{N}$-glycosides of this type yield specifically the beta-anomer [36]. While the ${ }^{4} \mathrm{C}_{1}$ conformation is known to be the lowest energy conformation of monosaccharides [37], previous DFT calculations of these complexes observed twist boat geometries as well [32]. A total of 29 initial geometries were generated allowing the coordination of the metal center to each

Table 1. $\mathrm{MS}^{\mathrm{n}}$ product ions from diasteromeric hexose complexes $\mathrm{m} / \mathrm{z} 364$ and $\mathrm{m} / \mathrm{z} 328$

\begin{tabular}{|c|c|c|c|c|c|c|c|}
\hline & $-\mathrm{H}_{2} \mathrm{O}$ & $-\mathrm{CH}_{2} \mathrm{O}$ & $\begin{array}{c}-\mathrm{CH}_{2} \mathrm{O} / \\
\mathrm{H}_{2} \mathrm{O}\end{array}$ & $-\mathrm{C}_{2} \mathrm{H}_{4} \mathrm{O}_{2}$ & $-\mathrm{C}_{3} \mathrm{H}_{6} \mathrm{O}_{3}$ & $-\mathrm{C}_{4} \mathrm{H}_{6} \mathrm{O}_{3}$ & $-\mathrm{C}_{4} \mathrm{H}_{8} \mathrm{O}_{4}$ \\
\hline$m / z 36$ & $328 \rightarrow$ & & & & & \multicolumn{2}{|c|}{ Precursor: [Zn/dien/Hex/Cl] $]^{+}$} \\
\hline Glc & & $x$ & & $x$ & & & $x$ \\
\hline Gal & $x$ & $x$ & & $x$ & $x$ & & $x$ \\
\hline Man & $x$ & $x$ & & & $x$ & & $x$ \\
\hline $\mathrm{m} / \mathrm{z} 32$ & & & & & & \multicolumn{2}{|c|}{ Precursor: $[\mathrm{Zn} / \text { dien/Hex }-\mathrm{H}]^{+}$} \\
\hline Glc & & $x$ & $x$ & $x$ & & $x$ & $x$ \\
\hline Gal & $x$ & $x$ & $x$ & $x$ & $x$ & $\mathrm{X}$ & $x$ \\
\hline Man & $x$ & $x$ & $x$ & $x$ & $x$ & & $x$ \\
\hline
\end{tabular}




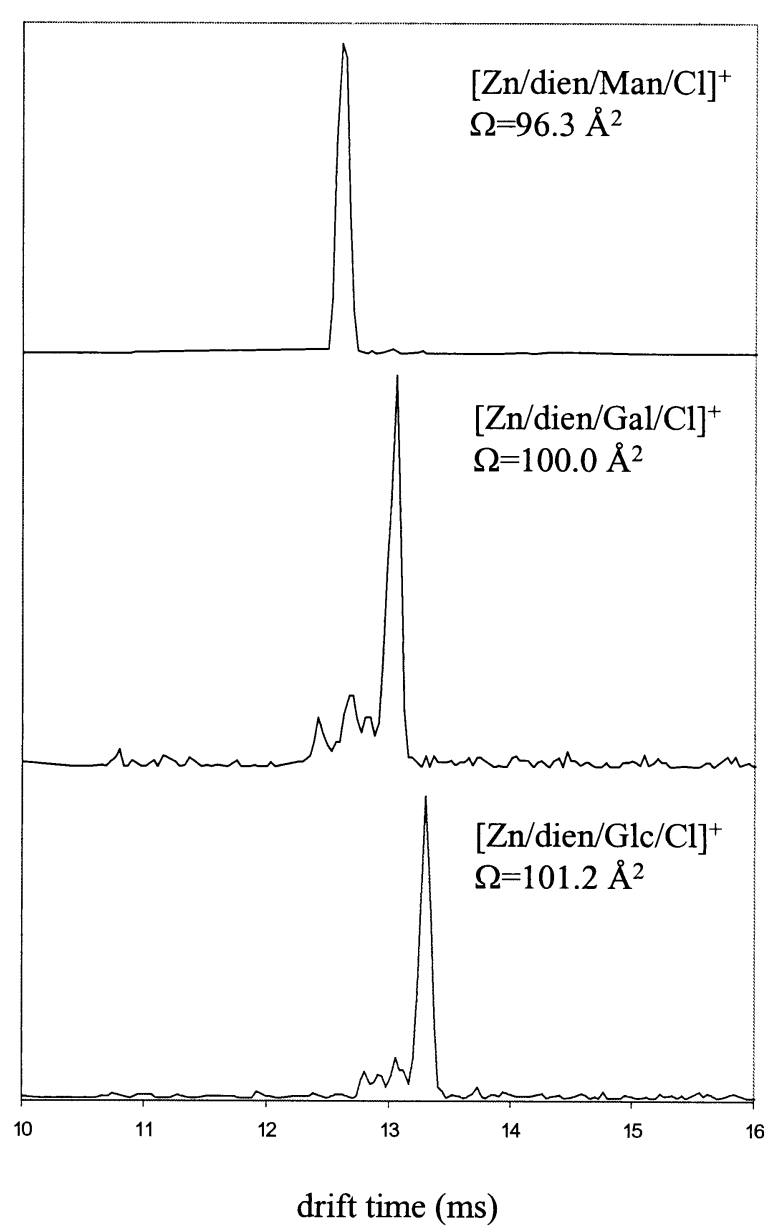

Figure 2. Ion mobility data for each of the diastereomeric complexes with the cross sections notated: $[\mathrm{Zn} / \text { dien/mannose } / \mathrm{Cl}]^{+}$ (top), [ $\mathrm{Zn} /$ dien/galactose $/ \mathrm{Cl}]^{+}$(middle), and $[\mathrm{Zn} /$ dien/glucose/ $\mathrm{Cl}]^{+}$(bottom). These data are obtained by taking horizontal slices across the two dimensional datasets (data not shown).

available hydroxyl group on the monosaccharide ring. In addition, the orientation of the $\mathrm{Zn}-\mathrm{Cl}$ bond was varied (up/down versus the plane formed by the $\mathrm{C} 2$, C3, C5, O5 atoms) to allow sampling of different chlorine locations. Upon fixing the coordination number of the metal, a quick geometry optimization of the complex was undertaken using the Sybyl force field [27]. The structures were further optimized using the ONIOM method $[28,29]$ as employed in Gaussian 98 for Windows [30]. Single-point calculations were carried out at the B3LYP / $6-31+\mathrm{G}^{*}$ level of theory to determine accurate energies. The theoretical cross section of each complex was determined by the trajectory method [25]. This method takes into account both scattering and potential interactions between the ion and the buffer gas allowing an accurate determination of theoretical cross section.

Upon completion of the geometry optimizations and single-point energy calculations, 29 geometries were found (Figure 3, Figure 7) that had a relative energy range between $0-220 \mathrm{~kJ} / \mathrm{mol}$. The relative energies are scaled to the lowest energy complex of each diastereomer. The minimum geometries can be separated into two main classes; those in which the metal center was coordinated to the C3 or the C4 hydroxyl group and those in which the metal center was coordinated to the $\mathrm{C} 2$ or the $\mathrm{C} 6$ hydroxyl group. In general the $\mathrm{C} 3$ and $\mathrm{C} 4$ coordinated structures yielded energies that were between $110-220 \mathrm{~kJ} / \mathrm{mol}$ higher than the lowest relative energy structure, while the C2 and C6 coordinated structures were between $0-110 \mathrm{~kJ} / \mathrm{mol}$ higher in energy than the lowest relative energy structure.

To judge the validity of the theoretically generated structures, search criteria must be set up based on the expected deviations of the theoretical data from the experimental data. The two search criteria employed are the relative energy and the theoretical cross section of each structure. In general, the theoretical cross sections generated from trajectory calculations, yields cross sections within $2 \%$ of the experimentally determined cross section [35]. Therefore, a deviation of no more than $2 \%$ is allowed for structures that are considered candidate structures. To estimate the expected energy error of the ONIOM method, two test calculations were undertaken on the Glc5 and Gal5 structures (Figure 7). In this test, molecules previously optimized using the ONIOM method were reoptimized at the B3LYP/ $6-31+\mathrm{G}^{*}$ level of theory. [The calculation time for such an optimization was 5 weeks/molecule. Therefore this method is considered unrealistic for a larger study of these molecules]. The difference in energy between the two methods reflects the inconsistencies of the ONIOM method (and the lower levels of theory employed) and the B3LYP/6-31+G* level of theory, which is the maximum calculation level employed in this study. The results (Table 2) indicate that an approximate energy error of $80 \mathrm{~kJ} / \mathrm{mol}$ results from employing the ONIOM method (with lower levels of theory) as opposed to B3LYP $/ 6-31+G^{*}$ for the optimization. Therefore, the authors propose a maximum energy window of $0-90$ $\mathrm{kJ} / \mathrm{mol}$ versus the lowest energy structure $(10 \mathrm{~kJ} / \mathrm{mol}$ were added as an additional buffer zone).

Figures 4,5 , and 6 are plots of the theoretical cross section versus the relative energy of each complex for the glucose, galactose, and mannose complexes respectively. The area of the plots enclosed in a shaded rectangle is the boundary of likely structures (i.e., the area in which likely structures should be found given the criteria stated above). Accordingly, the left and right boundaries correspond to the 0 and $90 \mathrm{~kJ} / \mathrm{mol}$ limits, while the top and bottom boundaries show the allowed $2 \%$ deviation from experimental cross section. All candidate structures that fit both the energy and cross section criteria are pictured in Figure 7.

Analysis of the generated glucose structures reveals complexes with relative energies ranging from $0-215$ $\mathrm{kJ} / \mathrm{mol}$ and theoretical cross sections between 95.8 and $106.5 \AA^{2}$ (Figure 4, Table 3). In general, structures with $\mathrm{O}(2)$ coordination to the metal had cross sections of approximately $106 \AA^{2}$, while $\mathrm{O}(4)$ and $\mathrm{O}(6)$ coordinated 


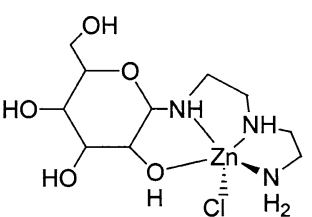

Glc1 Gal1 Man1 Man3-5

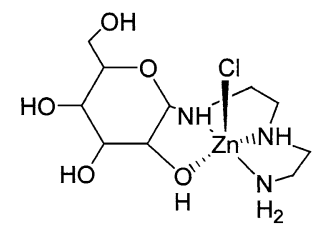

Glc2 Gal2 Man2

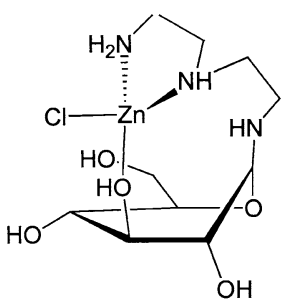

Glc3

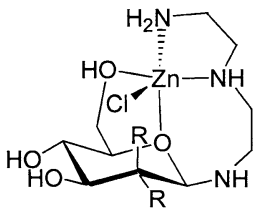

Glc4 Man12

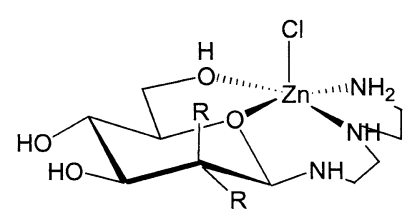

Glc6 Man14

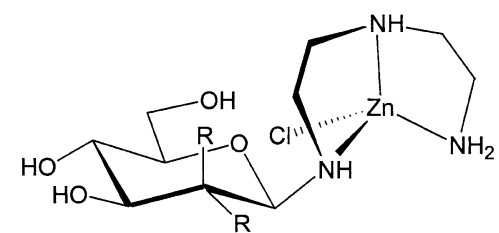

Glc8 Man13

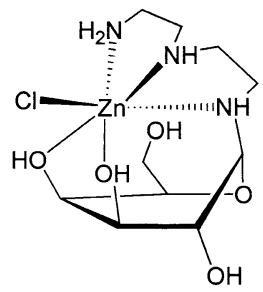

Gal3

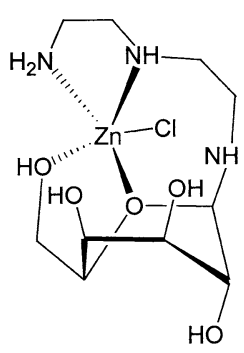

Gal4

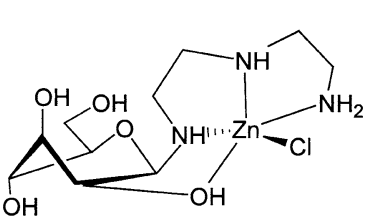

Man6

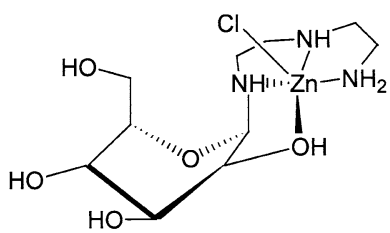

Man7,10

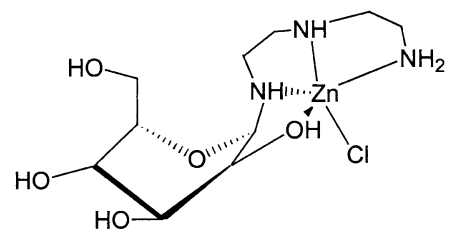

Man9

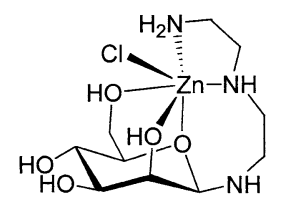

Man11

Figure 3. Structures that did not meet the energy and cross section search criteria $(\mathrm{R}=\mathrm{H}$ or $\mathrm{OH}$ depending on the identity of the monosaccharide). Designations for each monosaccharide are found below the structure. Where several structures of a given diastereomer are listed, only hydrogen bonding interactions have been changed, however, the monosaccharide, coordinating groups, and coordination geometry of the complexes are as shown (see Figure 7 for the structures that met the search criteria).

structures had theoretical cross sections between 96$100 \AA^{2}$. Given that the experimental cross section for glucose was measured as $101.2 \AA^{2}$, only $\mathrm{O}(4)$ and $\mathrm{O}(6)$ coordinated structures are likely. There was not a noticeable trend between relative energies and coordination site, however, the $\mathrm{O}(4)$ coordinated structure had a very large relative energy of ca. $214 \mathrm{~kJ} / \mathrm{mol}$. Using the criteria explained above for determining the validity of calculated structures, only two of the eight structures were found as possible candidates for the experimentally observed structures. Each of these structures had $\mathrm{O}(6)$ coordinated to the metal and are depicted in Figure 7 and designated as structures Glc5 and Glc7.

Structure Glc5 was found to have a theoretical cross section of $99.6 \AA^{2}$ versus the experimentally measured cross section of $101.2 \AA^{2}$, yielding a $1.6 \%$ error. The relative energy of this structure was found to be 31.0 $\mathrm{kJ} / \mathrm{mol}$ which is reasonable under the allowed energy error as described above. The $\mathrm{Zn}$ (II) metal center is found to be 5-coordinate in a distorted trigonal bipyramidal geometry. The coordinating atoms are: $\mathrm{N}(2)$, $\mathrm{N}(3), \mathrm{Cl}, \mathrm{O}(5)$, and $\mathrm{O}(6)$, where the $\mathrm{O}(6), \mathrm{N}(2)$, and the $\mathrm{Cl}$ atoms comprise the trigonal plane, while the $\mathrm{N}(3)$ and $\mathrm{O}(5)$ atoms reside in the pseudoaxial positions. The extent of the distortion is exemplified by the $\mathrm{O}(5)-\mathrm{Zn}-$ $N(3)$ angle which measures $\sim 162^{\circ}$. Trigonal bypyramidal geometries of this type have been observed in crystal structures by Tolman and coworkers in their

Table 2. Results from the energy error calculations

\begin{tabular}{|c|c|c|c|}
\hline $\begin{array}{l}\text { Table } \\
\text { key }\end{array}$ & $\begin{array}{c}\mathrm{E}_{\mathrm{B} 3 \mathrm{LYP} / 6-31+\mathrm{G} * / / \mathrm{ONIOM}} \\
\text { (Hartrees) }\end{array}$ & $\begin{array}{c}\mathrm{E}_{\mathrm{B} 3 \mathrm{LYP} / 6-31}+\mathrm{G}^{* / / B} 3 \mathrm{LYP} / 6-31+\mathrm{G}^{*} \\
\text { (Hartrees) }\end{array}$ & $\begin{array}{l}\text { Error }^{\mathrm{a}} \\
(\mathrm{kJ} / \mathrm{mol})\end{array}$ \\
\hline Glc5 & -3174.526 & -3174.556 & 78.8 \\
\hline Gal5 & -3174.529 & -3174.559 & 78.8 \\
\hline
\end{tabular}

${ }^{a}$ Error $=\left|E_{\left(B 3 L Y P / 6-31+G^{*} / B 3 L Y P / 6-31+G^{*}\right)}-E_{\left(B 3 L Y P / 6-31+G^{*} / / O N I O M\right)}\right|$ 
Glucose $\left(101.2 \AA^{2}\right)$

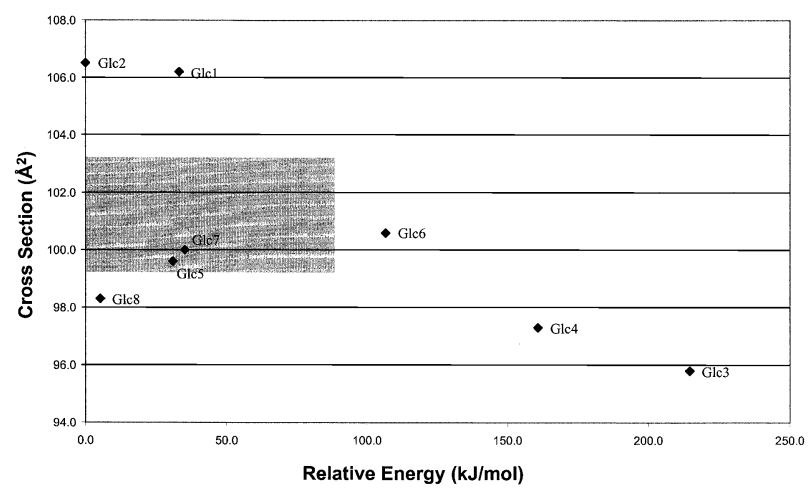

Figure 4. Cross section versus energy plots for the theoretically generated structures of $[\mathrm{Zn} / \operatorname{dien} / \mathrm{Glc} / \mathrm{Cl}]^{+}$. The structures enclosed in the grey box are those that satisfy the energy and cross section criteria discussed in the text.

investigation of $\mathrm{Zn}$ (II) and $\mathrm{Cu}$ (II) complexes [38]. All $\mathrm{Zn}$-coordinating bond lengths were between 1.98-2.19 $\AA$. The monosaccharide ring conformation was found to occupy the ${ }^{4} \mathrm{C}_{1}$ conformation, which was previously observed in theoretical calculations of $\mathrm{Ni}(\mathrm{II}) /$ diaminopropane/glucose complexes [32].

Structure Glc7 exhibited a theoretical cross section of $100.0 \AA^{2}$ which deviates $1.2 \%$ from the experimental cross section. The relative energy of the complex is ca. 35 $\mathrm{kJ} / \mathrm{mol}$ as compared to the lowest energy glucose structure. As in structure 1, the monosaccharide ring conformation was found to occupy the ${ }^{4} \mathrm{C}_{1}$ ring conformation. However, in this case the metal center was found to be 6-coordinate in a heavily distorted octahedron. The chelating atoms were found to be $\mathrm{O}(5), \mathrm{O}(6)$, $\mathrm{N}(1), \mathrm{N}(2), \mathrm{N}(3)$, and $\mathrm{Cl}$. Geometry distortion is due to the heavily strained 4-membered ring made up of $\mathrm{O}(5)$, $\mathrm{C}(1), \mathrm{N}(1)$, and $\mathrm{Zn}(\mathrm{II})$. Measurements of the metalchelating atom bond lengths yield distances of between 2.01-2.45 A. Vahrenkamp and coworkers [39] have

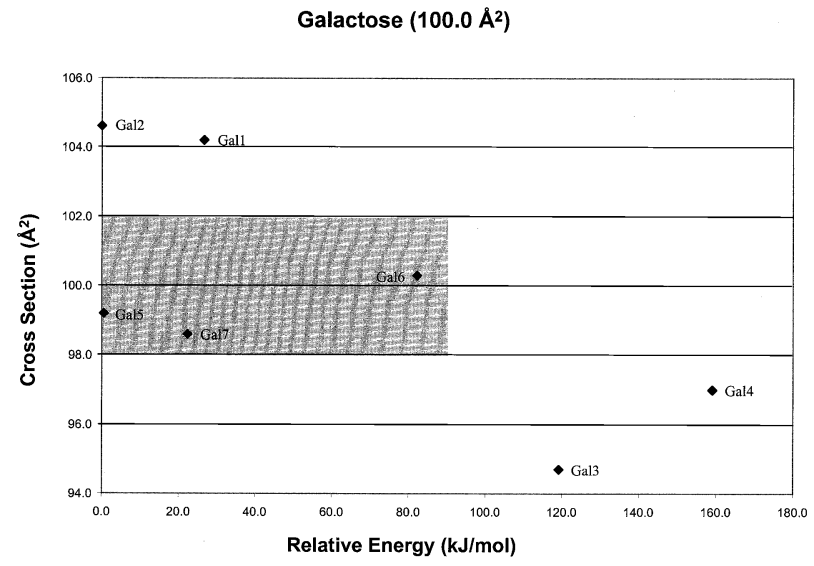

Figure 5. Cross section versus energy plots for the theoretically generated structures of $[\mathrm{Zn} / \mathrm{dien} / \mathrm{Gal} / \mathrm{Cl}]^{+}$. The structures enclosed in the grey box are those that satisfy the energy and cross section criteria discussed in the text.

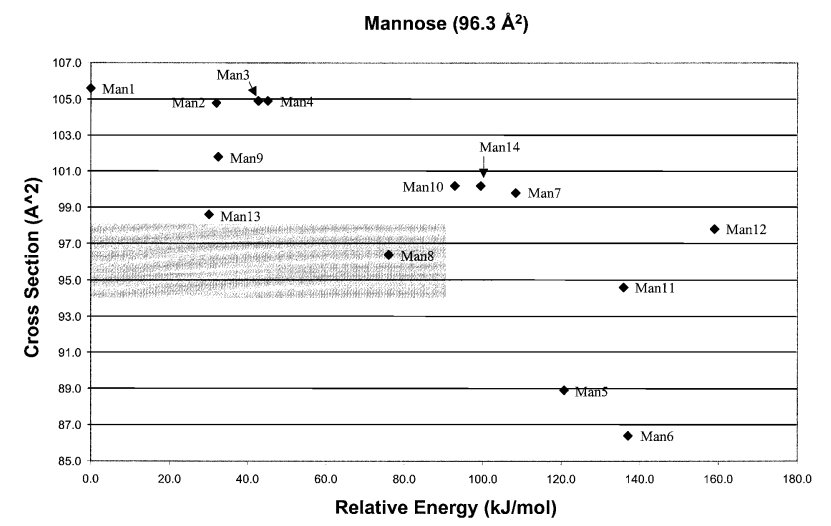

Figure 6. Cross section versus energy plots for the theoretically generated structures of $[\mathrm{Zn} / \text { dien } / \mathrm{Man} / \mathrm{Cl}]^{+}$. The structures enclosed in the grey box are those that satisfy the energy and cross section criteria discussed in the text.

found these types of complexes before in their investigation of tripodal $\mathrm{N}_{3} \mathrm{O}$ ligands in complex with $\mathrm{Zn}(\mathrm{II})$.

A total of seven structures were calculated for the galactose complexes (Figure 5, Table 4). Metal coordination was varied between the $\mathrm{O}(2), \mathrm{O}(4)$, and $\mathrm{O}(6)$ hydroxyl groups, thus examining all possible coordinating geometries. $\mathrm{O}(2)$ metal coordination yielded theoretical cross sections that were larger than the experimental cross section $\left(100.0 \AA^{2}\right)$ with approximately $5 \%$ error, while $\mathrm{O}(4)$ coordination yielded structures with smaller cross sections than experimentally measured, yielding structures with between 3 and $5 \%$ error. As a result, both $\mathrm{O}(2)$ and $\mathrm{O}(4)$ coordination sites are ruled out as candidate structures.

The $\mathrm{O}(4)$-coordinated structures were found to have a large relative energy $(\sim 160 \mathrm{~kJ} / \mathrm{mol}$ or higher) for the complexes investigated. The energy increase arises
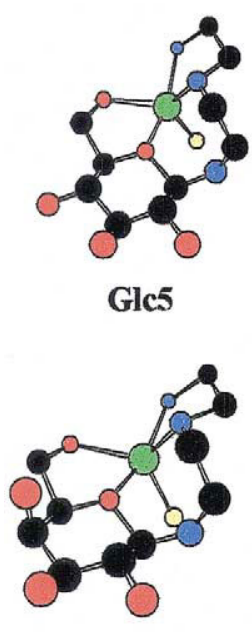

Gal5

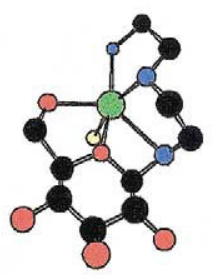

Glc7

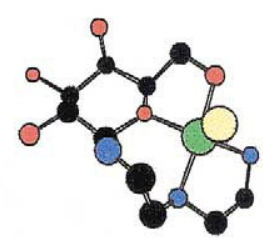

Gal6

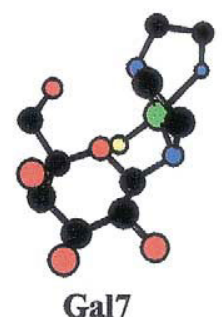

Gal7

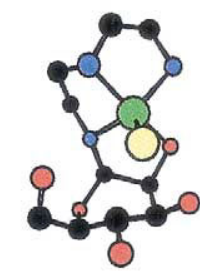

Man8
Figure 7. Candidate structures for the complexes observed in the ion mobility mass spectrometer. CPK colors are used to designate the atoms (e.g., black $=$ carbon, blue $=$ nitrogen, red = oxygen, green $=$ zinc, and yellow $=$ chlorine). Hydrogen atoms are omitted for clarity. 
Table 3. Results from DFT and trajectory calculations on the $[\mathrm{Zn} / \text { dien/Glc/Cl }]^{+}$

\begin{tabular}{|c|c|c|c|c|}
\hline $\begin{array}{l}\text { Table } \\
\text { key }^{\mathrm{a}}\end{array}$ & $\begin{array}{c}\text { Relative } \\
\text { energy } \\
(\mathrm{kJ} / \mathrm{mol})\end{array}$ & $\begin{array}{c}\text { Theoretical } \\
\text { cross } \\
\text { section } \\
\left(\AA^{2}\right)\end{array}$ & $\begin{array}{c}\text { Actual } \\
\text { cross } \\
\text { section } \\
\left(\AA^{2}\right)\end{array}$ & $\begin{array}{c}\text { Percent } \\
\text { error }\end{array}$ \\
\hline Glc1 & 33.1 & 106.2 & 101.2 & $4.9 \%$ \\
\hline Glc2 & 0.0 & 106.5 & & $5.2 \%$ \\
\hline Glc3 & 214.6 & 95.8 & & $5.3 \%$ \\
\hline Glc4 & 160.7 & 97.3 & & $3.9 \%$ \\
\hline $\mathrm{Glc}^{\mathrm{b}}$ & 31.0 & 99.6 & & $1.6 \%$ \\
\hline Glc6 & 106.6 & 100.6 & & $0.6 \%$ \\
\hline $\mathrm{Glc}^{\mathrm{b}}$ & 35.2 & 100.0 & & $1.2 \%$ \\
\hline Glc8 & 5.3 & 98.3 & & $2.9 \%$ \\
\hline
\end{tabular}

a See Figures 3 and 7 for pictures of the individual complexes. Compounds are numbered here as in Figure 4.

bThe highlighted structures meet the search criteria discussed in the text.

from steric hindrance between the axial $\mathrm{C}(4)$ position and the bulky metal-ligand complex at the $\mathrm{C}(1)$ position (Figure 8). This type of repulsion is expected for the glucose and the mannose monomers, where the $\mathrm{O}(4)$ hydroxyl group is in the equatorial position and consequently, the metal cannot reach the $\mathrm{O}(4)$ site without sacrificing other more favorable interactions. However, one may expect the opposite to be true with the galactose sugar, since the $\mathrm{O}(4)$ hydroxyl group occupies the axial position allowing coordination to occur. In fact, coordination to the $\mathrm{O}(4)$ hydroxyl group is possible, however this coordination forces the monosaccharide ring into an envelope conformation $\left({ }^{1} \mathrm{E}\right.$ see structure Gal3, Figure 3), which is predicted to be $\sim 70$ $\mathrm{kJ} / \mathrm{mol}$ higher in energy than the ${ }^{4} \mathrm{C}_{1}$ in the underivatized monosaccharide [37]. Therefore, addition of the metal-ligand system adds an extra steric strain to the complex, which is exemplified in the monosaccharide conformation as well as in the metal coordination environment. This results in the observed instability of these $\mathrm{O}(4)$-coordinated complexes.

It was the $\mathrm{O}(6)$ coordination site that yielded structures with cross sections within the appropriate error $<2 \%$. Examination of the relative energies of these structures shows that all three $\mathrm{O}(6)$ coordinated complexes are within a reasonable energy range. Complexes are shown in Figure 7 and they are designated as structures Gal7, Gal5, and Gal6.

Structure Gal7 was found to have a relative energy of $30.2 \mathrm{~kJ} / \mathrm{mol}$ and a theoretical cross section of $98.6 \AA^{2}$ thus yielding a $1.4 \%$ error between the theoretically determined and the experimentally measured cross sections. A 4-coordinate $\mathrm{Zn}$ (II) is observed in a tetrahedral geometry with the $\mathrm{N}(1), \mathrm{N}(2), \mathrm{N}(3)$, and the $\mathrm{Cl}$ atoms coordinating. The tetrahedral geometry is slightly distorted with angles between $109-123^{\circ}$, which is expected because of the tridentate interaction of the chelating diethylenetriamine ligand. Bond lengths are also within normal ranges measuring 1.96-2.01 $\AA$.

Both structures Gal5 and Gal6 were found to have 5-coordinate $\mathrm{Zn}$ (II) metal centers with different coordinating geometries. Structure Gal5 was found to have a distorted trigonal bipyramidal geometry with $\mathrm{N}(2)$, $\mathrm{N}(3), \mathrm{O}(6), \mathrm{O}(5)$, and $\mathrm{Cl}$ coordinating the metal center. The $\mathrm{N}(2), \mathrm{O}(6)$, and $\mathrm{Cl}$ atoms comprise the trigonal plane, while $\mathrm{O}(5)$ and $\mathrm{N}(3)$ reside in the pseudoaxial positions. Bond lengths range from 1.98-2.20 $\AA$, while the $\mathrm{O}(5)-\mathrm{Zn}(\mathrm{II})-\mathrm{N}(3)$ atoms make $\sim 163^{\circ}$ angle. The coordinating geometry around the $\mathrm{Zn}(\mathrm{II})$ metal center in structure Gal6 was found be a distorted square pyramid with the $\mathrm{N}(2), \mathrm{N}(3), \mathrm{O}(5), \mathrm{O}(6)$, and $\mathrm{Cl}$ atoms coordinating to the $\mathrm{Zn}(\mathrm{II})$ and the $\mathrm{Cl}$ atom occupying

Table 4. Results from DFT and trajectory calculations on the $[\mathrm{Zn} / \mathrm{dien} / \mathrm{Gal} / \mathrm{Cl}]^{+}$

\begin{tabular}{lcccc}
\hline $\begin{array}{l}\text { Table } \\
\text { key }^{\text {a }}\end{array}$ & $\begin{array}{c}\text { Relative } \\
\text { energy } \\
(\mathrm{kJ} / \mathrm{mol})\end{array}$ & $\begin{array}{c}\text { Theoretical } \\
\text { cross } \\
\text { section } \\
\left(\AA^{2}\right)\end{array}$ & $\begin{array}{c}\text { Actual } \\
\text { cross } \\
\text { section } \\
\left(\AA^{2}\right)\end{array}$ & $\begin{array}{c}\text { Percent } \\
\text { error }\end{array}$ \\
\hline \hline Gal1 & 26.6 & 104.2 & 100.0 & $4.2 \%$ \\
Gal2 & 0.0 & 104.6 & & $4.6 \%$ \\
Gal3 & 119.2 & 94.7 & $5.3 \%$ \\
Gal4 & 159.1 & 97.0 & $3.0 \%$ \\
Gal5 & 0.5 & 99.2 & $0.8 \%$ \\
Gal6 $^{\text {b }}$ & 82.2 & 100.3 & $0.3 \%$ \\
Gal7 $^{\text {b }}$ & 22.3 & 98.6 & $1.4 \%$ \\
\hline
\end{tabular}

aSee Figures 3 and 7 for pictures of the individual complexes. Compounds are numbered here as in Figure 5.

bThe highlighted structures meet the search criteria discussed in the text. 


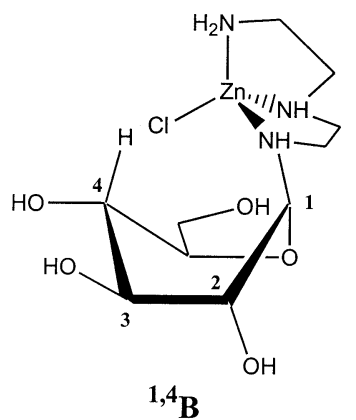

Glucose
Galactose

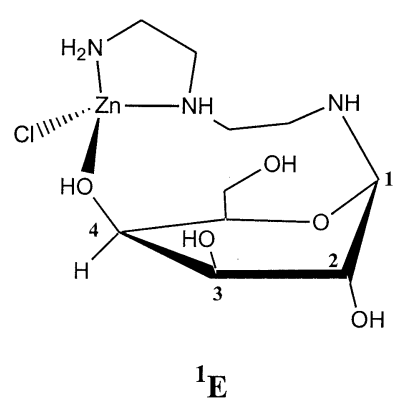

Figure 8. Steric hindrance encountered when $\mathrm{O}(4)$ coordination is attempted for the glucose and galactose monosaccharides which have an equatorial $\mathrm{O}(4)$ and an axial $\mathrm{O}(4)$, respectively.

the apex. Again, normal bond lengths are observed ranging between $1.98-2.15 \AA$. It is not surprising that these two galactose structures exhibit both the trigonal bipyramidal and the square pyramidal geometries. Both the trigonal bipyramidal and the square pyramidal geometries are known to be comparable in energy, with only a small energy barrier between the two extremes [40]. Therefore, in many cases the structures are distorted in such a way that they occupy an intermediate geometry. This distortion is observed in all 5-coordinate structures shown. Structures Gal5 and Gal6 have cross sections that deviate less than $1 \%$ from the experimental cross section and are $99.2 \AA^{2}$ and $100.3 \AA^{2}$ for structures Gal5 and Gal6, respectively. The relative energies are vastly different for these two structures. Structure Gal5 was found to have a relative energy of only $0.5 \mathrm{~kJ} / \mathrm{mol}$, while structure Gal6 was found to have a relative energy of $82.2 \mathrm{~kJ} / \mathrm{mol}$.

Examination of the generated mannose structures yields several complexes with an energy range of $0.0-$
$159.0 \mathrm{~kJ} / \mathrm{mol}$ and cross sections that vary from 86.4$105.6 \AA^{2}$ (Figure 6, Table 5). Of the 14 possible structures, several fall within the allowed energy range; however, only one structure falls within the allowed cross-section range. This structure (Man8) was found to have a theoretical cross section of $96.4 \AA^{2}$ and a relative energy of $76.1 \mathrm{~kJ} / \mathrm{mol}$ (the measured cross section of mannose was found to be $96.3 \AA^{2}$ ). Investigation of the complex shows that a $B_{3,0}$ sugar ring conformation was adopted in the mannose structure. It is important to note that this unique structure was arrived at only after an extensive search of the different chair conformations that were found to predominate for both the galactose and glucose complexes.

Generally, the ${ }^{4} \mathrm{C}_{1}$ chair conformation is accepted as being the most stable monosaccharide conformation. Molecular mechanics studies indicate that the energy difference between the ${ }^{4} \mathrm{C}_{1}$ and the $\mathrm{B}_{3,0}$ conformation is approximately $40 \mathrm{~kJ} / \mathrm{mol}$ [37]. This preference is mirrored for the galactose and glucose complexes as discussed above, however, mannose does not follow this trend. The proposed mannose conformation can be explained through the stereochemistry of the pyranose ring. The $B_{3,0}$ ring conformation is unique because in this conformation, metal coordination to both $\mathrm{N}(1)$ and the $\mathrm{O}(2)$ can only occur to a monosaccharide with an axial C(2) hydroxyl group, such as mannose (Figure 9). Thus, the coordinating $\mathrm{N}(1)$ and $\mathrm{O}(2)$ groups are aligned in a gauche fashion upon adoption of the $B_{3,0}$ conformation, while a $\mathrm{N}(1), \mathrm{O}(2)$ coordination could not occur for galactose and glucose upon adoption of the $B_{3,0}$ conformation because the coordinating groups would adopt an anti geometry.

The coordination geometry of the metal center was found to be a 5-coordinate distorted square pyramid, where the $\mathrm{Cl}$ atom occupies the axial position, while the three nitrogens of the dien ligand and $\mathrm{O}(2)$ were found to occupy the equatorial positions. Analysis of the bond

Table 5. Results from DFT and trajectory calculations on the $[\mathrm{Zn} / \mathrm{dien} / \mathrm{Man} / \mathrm{Cl}]^{+}$

\begin{tabular}{|c|c|c|c|c|}
\hline $\begin{array}{l}\text { Table } \\
\text { key }^{\text {a }}\end{array}$ & $\begin{array}{c}\text { Relative } \\
\text { energy } \\
(\mathrm{kJ} / \mathrm{mol})\end{array}$ & $\begin{array}{c}\text { Theoretical } \\
\text { cross } \\
\text { section } \\
\left(\AA^{2}\right)\end{array}$ & $\begin{array}{c}\text { Actual } \\
\text { cross } \\
\text { section } \\
\left(\AA^{2}\right)\end{array}$ & $\begin{array}{c}\text { Percent } \\
\text { error }\end{array}$ \\
\hline Man1 & 0.0 & 105.6 & 96.3 & $9.7 \%$ \\
\hline Man2 & 32.0 & 104.8 & & $8.8 \%$ \\
\hline Man3 & 42.7 & 104.9 & & $8.9 \%$ \\
\hline Man4 & 45.1 & 104.9 & & $8.9 \%$ \\
\hline Man5 & 120.7 & 88.9 & & $-7.7 \%$ \\
\hline Man6 & 137.0 & 86.4 & & $-10.3 \%$ \\
\hline Man7 & 108.4 & 99.8 & & $3.6 \%$ \\
\hline Man $^{b}$ & 76.1 & 96.4 & & $0.1 \%$ \\
\hline Man9 & 32.5 & 101.8 & & $5.7 \%$ \\
\hline Man10 & 92.9 & 100.2 & & $4.0 \%$ \\
\hline Man11 & 135.9 & 94.6 & & $1.8 \%$ \\
\hline Man12 & 159.0 & 97.8 & & $1.6 \%$ \\
\hline Man13 & 30.2 & 98.6 & & $2.4 \%$ \\
\hline Man14 & 99.4 & 100.2 & & $4.0 \%$ \\
\hline
\end{tabular}

asee Figures 3 and 7 for pictures of the individual complexes. Compounds are numbered here as in Figure 6.

bThe highlighted structures meet the search criteria discussed in the text. 


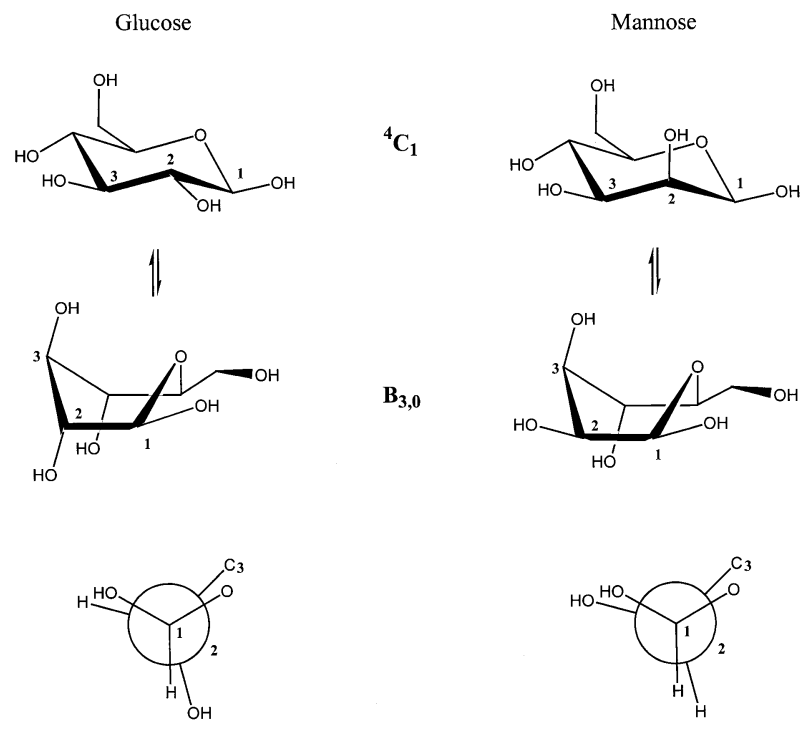

Figure 9. Availability of the $\mathrm{O}(2)$ hydroxyl group for binding to the metal center for different ring conformations and the glucose and mannose monomers.

lengths between the $\mathrm{Zn}$ and the coordinating atoms, yields distances of 2.0-2.2 $\AA$, while bond angles range from $105-114^{\circ}$. As was discussed earlier, distortion away from the trigonal bipyramidal and square pyramidal geometries is common in the 5-coordinate complexes, since the energetic differences between the two coordinating geometries is small.

\section{Conclusions}

In this study different coordination geometries, coordination numbers, and monosaccharide conformations were investigated using ion mobility methods and density functional theory calculations, to determine likely complex geometries in the gas phase of [Zn(II)/ diethylenetriamine $/$ Hexose $/ \mathrm{Cl}]^{+}($Hexose $=$glucose, galactose, or mannose) diastereomeric complexes. This investigation was undertaken to probe the conformation of these complexes before collisional activation. The resulting structures can be used in determining the stereoselective dissociation mechanisms, which is the subject of a future study. Ion mobility studies indicate that the conformations of the diastereomeric complexes are different and that the mannose $\left(96.3 \AA^{2}\right)$ complex is more compact than the galactose $\left(100.0 \AA^{2}\right)$ and glucose $\left(101.2 \AA^{2}\right)$ complexes respectively. Two search criteria were developed to determine the validity of the calculated structures, which are: (1) That the relative energy of the complexes are within $0-90 \mathrm{~kJ} / \mathrm{mol}$ of the lowest energy structure and (2) the theoretical cross section deviates by no more that $2 \%$ of the experimental cross section. Probable complex geometries had coordination numbers ranging from four to six, with tetrahedral, trigonal bipyramid, square pyramidyl, and octahedral coordination geometries. The monosaccharide occupied either the chair or twist-boat conformations in all prob- able complexes. These studies indicate that the galactose and glucose complexes have metal coordination to the $\mathrm{O}(6)$ hydroxyl group, and the monosaccharide conformation exists in the ${ }^{4} C_{1}$ chair conformation. However, the mannose complex has metal coordination to the $\mathrm{O}(2)$ hydroxyl group, with a $\mathrm{B}_{3,0}$ monosaccharide conformation. Therefore, it is apparent that the stereochemistry of the carbohydrate/dien complex dictates the conformation and the metal coordination within the compound.

\section{Acknowledgments}

JAL acknowledges the NIH (GM 47356) for financial support. DEC acknowledges the NSF (CHE-0078737) for financial support.

\section{References}

1. Liu, Y.; Valentine, S. J.; Counterman, A. E.; Hoaglund, C. S.; Clemmer, D. E. Injected-Ion Mobility Analysis of Biomolecules. Anal. Chem. 1997, 69, 728A-735A.

2. Clemmer, D. E.; Jarrold, M. F. Ion Mobility Measurements and their Applications to Clusters and Biomolecules. J. Mass Spectrom. 1997, 32, 577-592.

3. Kinnear, B. S.; Kaleta, D. T.; Kohtani, M.; Hidgins, R. R.; Jarrold, M. F. Conformations of Unsolvated Valine-Based Peptides. J. Am. Chem. Soc. 2000, 122, 9243-9256.

4. Taraszka, J. A.; Li, J. W.; Clemmer, D. E. Metal-Mediated Peptide Ion Conformations in the Gas Phase. J. Phys. Chem. B 2000, 104, 4545-4551.

5. Wyttenbach, T.; Witt, M.; Bowers, M. T. On the Question of Salt Bridges of Catonized Amino Acids in the Gas Phase. Int. J. Mass Spectrom. 1999, 182/183, 243-252.

6. Hill, H. H., Jr.; Matz, L. M. Evaluation of Opiate Separation by High-Resolution Electrospray Ionization-Ion Mobility Spectrometry Mass Spectrometry. Anal. Chem. 2001, 73, 1664-1669.

7. Henderson, S. C.; Valentine, S. J.; Countermann, A. E.; Clemmer, D. E. ESI/Ion Trap/Ion Mobility/Time-of-Flight Mass Spectrometry for Rapid and Sensitive Analysis of Biomolecular Mixtures. Anal. Chem. 1999, 71, 291-301.

8. Gyurcsik, B.; Nagy, L. Carbohydrates as Ligands: Coordination Equilibria and Structure of the Metal Complexes. Coord. Chem. Rev. 2000, 203, 81-149.

9. Rao, V. S. R.; Qasba, P. K.; Balaji, P. V.; Chandrasekaran, R. Conformation of Carbohydrates. Hardwood Academic: Amsterdam, 1998; pp 156-160.

10. Sinnott, M. L. Catalytic Mechanisms of Enzymatic Glycosyl Transfer. Chem. Rev. 1990, 90, 1171-1202.

11. Huebers, H. Iron Overload: Pathogenesis and Treatment with Chelating Agents. Blut 1983, 47, 61-67.

12. Burger, K.; Zay, I.; Nagy, G. T. A Novel Polynuclear Iron(III) Mixed Ligand Complex for Use in Parenteral Iron Therapy. Inorg. Chim. Acta 1983, 80, 231-235.

13. Berg, K. A.; Bowen, L. H.; Hedges, S. W.; Bereman, R. D.; Vance, C. T. Identification of Ferrihydrite in Polysaccharide Iron Complex by Moessbauer Spectroscopy and X-Ray Differaction. J. Inorg. Biochem. 1984, 22, 125-135.

14. Smith, G.; Leary, J. A. Differentiation of Diastereomeric Nickel(II) N-Glycoside Complexes Using Tandem Mass Spectrometry and Kinetic Energy Release Measurements. J. Am. Chem. Soc. 1996, 118, 3293-3294.

15. Gaucher, S. P.; Leary, J. A. Stereochemical Differentiation of Mannose, Glucose, Galactose, and Talose Using Zn(II) Diethylenetriamine and ESI-Ion Trap Mass Spectrometry. Anal. Chem. 1998, 14, 3009-3014. 
16. Gaucher, S. P.; Leary, J. A. Determining Anomericity of the Glycosidic Bond in Zn(II)-Diethylenetriamine-Disaccharide Complexes Using MS ${ }^{n}$ in a Quadrupole Ion Trap. J. Am. Soc. Mass Spectrom. 1998, 10, 269-272.

17. Smith, G.; Kaffashan, A.; Leary, J. A. Influence of Coordination Number and Ligand Size on the Dissociation Mechanisms of Transition Metal-Monosaccharide Complexes. I. J. Mass Spectrom. Ion Processes 1999, 182/183, 299-310.

18. Desaire, H.; Leary, J. A. Multicomponent Quantification of Diastereomeric Hexosamine Monosaccharides Using Ion Trap Tandem Mass Spectrometry. Anal. Chem. 1999, 71, 4142-4147.

19. Desaire, H.; Leary, J. A. Differentiation of Diastereomeric N-Acetylhexosamine Monosaccharides Using Ion Trap Tandem Mass Spectrometry. Anal. Chem. 1999, 71, 1997-2002.

20. Gaucher, S. P.; Leary, J. A. Influence of Metal Ion and Coordination Geometry on the Gas Phase Dissociation and Stereochemical Differentiation of N-Glycosides. I. J. Mass Spectrom. 2000, 197, 139-148.

21. Desaire, H. D.; Beyer, M. K.; Leary, J. A. Molecular Orbital Considerations in Probing the Stereoselective Dissociations of Cobalt-Coordinated Hexosamine Monosaccharides. J. Am. Soc. Mass Spectrom. 2001, 12, 517-527.

22. Hoaglund, C. S.; Valentine, S. J.; Sporleader, C. R.; Reilly, J. P.; Clemmer, D. E. Three-Dimensional Ion Mobility TOFMS Analysis of Electrosprayed Biomolecules. Anal. Chem. 1998, 70, 2236.

23. Srebalus, C. A.; Li, J.; Marshall, W. S.; Clemmer, D. E. Three-Dimensional Ion Mobility TOFMS Analysis of Electrosprayed Biomolecules. Anal. Chem. 1999, $71,3918$.

24. Mason, E. A.; McDaniel, E. W. Transport Properties of Ions in Gases. Wiley: New York, 1988, pp 1-17 .

25. Mesleh, M. F.; Hunter, J. M.; Shvartsburg, A. A.; Schatz, G. C. Structural Information from Ion Mobility MeasurementsEffects of the Long-Range Potential. J. Phys. Chem. 1996, 100, 16082.

26. SPARTAN version 4.1.1, Wavefunction, Inc.; Irvine, CA.

27. Clark, M.; Cramer, R. D., III; van Opdensch, N. Validation of the General Purpose Tripos 5.2 Force Field. J. Comput. Chem. 1989, 10, 982.

28. Dapprich, S.; Komaromi, I.; Byun, K. S.; Morokuma, K.; Frisch, M. J. A New Oniom Implementation for the Calculation of Energies, Gradients and Higher Derivatives Using Mechanical and Electronic Embedding. I. Theo. Chem. 1999, 462, 1-21.

29. Komaromi, I.; Dapprich, S.; Byun, K. S.; Morokuma, K.; Frisch, M. J. A New Oniom Implementation for the Calculation of
Energies, Gradients and Higher Derivatives Using Mechanical and Electronic Embedding. II. Theo. Chem. unpublished.

30. Frisch, M. J.; Trucks, G. W.; Schlegel, H. B.; Scuseria, G. E.; Robb, M. A.; Cheeseman, J. R.; Zakrzewski, V. G.; Montgomery, J. A., Jr.; Stratmann, R. E.; Burant, J. C.; Dapprich, S.; Millam, J. M.; Daniels, A. D.; Kudin, K. N.; Strain, M. C.; Farkas, O.; Tomasi, J.; Barone, V.; Cossi, M.; Cammi, R.; Mennucci, B.; Pomelli, C.; Adamo, C.; Clifford, S.; Ochterski, J.; Petersson, G. A.; Ayala, P. Y.; Cui, Q.; Morokuma, K.; Malick, D. K.; Rabuck, A. D.; Raghavachari, K.; Foresman, J. B.; Cioslowski, J.; Ortiz, J. V.; Baboul, A. G.; Stefanov, B. B.; Liu, G.; Liashenko, A.; Piskorz, P.; Komaromi, I.; Gomperts, R.; Martin, R. L.; Fox, D. J.; Keith, T.; Al-Laham, M. A.; Peng, C. Y.; Nanayakkara, A.; Gonzalez, C.; Challacombe, M.; Gill, P. M. W.; Johnson, B.; Chen, W.; Wong, M. W.; Andres, J. L.; Head-Gordon, M.; Replogle, E. S.; Pople, J. A. Gaussian 98, Revision A.7. Gaussian, Inc: Pittsburgh, PA, 1998.

31. Dewar, M. J. S.; Zoebisch, E. G.; Healy, E. F.; Stewart, J. J. P. J. Am. Chem. Soc. 1985, 107, 3902.

32. Smith, G.; Leary, J. A. Mechanistic Studies of Diastereomeric Nickel(II) N-Glycoside Complexes Using Tandem Mass Spectrometry. J. Am. Chem. Soc. 1998, 120, 13046-13056.

33. Yano, S. Coordination Compounds Containing Sugars and Their Derivatives. Coord. Chem. Rev. 1988, 92, 113.

34. Wyttenbach, T.; von Helden, G.; Bowers, M. T. Gas-Phase Conformation of Biological Molecules-Bradykinin. J. Am. Chem. Soc. 1996, 118, 8355.

35. Clemmer, D. E.; Hudgins, R. R.; Jarrold, M. F. Naked Protein Conformations-Cytochrome C in the Gas Phase. J. Am. Chem. Soc. 1995, 117, 10141.

36. Gaucher, S. P.; Pedersen, S. F.; Leary, J. A. Stereospecific Synthesis and Characterization of Aminoglycoside Ligands from Diethylenetriamine. J. Org. Chem. 1999, 64, 4012-4015.

37. Dowd, M. K.; French, A. D.; Reilly, P. J. Modeling of Aldopyranosyl Ring Puckering with MM3(92). Carbohydrate Research 1994, 264, 1-19.

38. Halfen, J. A.; Jazdzewski, B. A.; Mahapatra, S.; Berreau, L. M.; Wilkinson, E. C.; Que, L., Jr.; Tolman, W. B. Synthetic Model of the Inactive Copper(II)-Tyrosinate and Active Copper(II)-Tyrosyl Radical Forms of Galactose and Glyoxal Oxidases. JACS 1997, 119, 8217-8227.

39. Trösch, A.; Vahrenkamp, H. Zinc Complexes of Tripodal $\mathrm{N}_{3} \mathrm{O}$ Ligands. Eur. J. Inorg. Chem. 1998 1998, 827-832.

40. Purcell, K. F.; Kotz, J. C. Inorganic Chemistry. W. B. Saunders Company: Japan, 1985; pp 587-603. 